\title{
GESCHICHTE DER ERDE \\ UND DES LEBENS
}

VON

JOHANNES WALTHER

O. O. PROFESSOR DER GEOLOGIE UND PALAONTOLOGIE AN DER UNIVERSITAT HALLE

MIT 353 ABBILDUNGEN

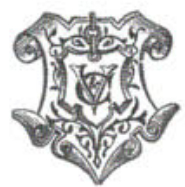

LEIPZIG

VERLAG VON VEIT \& COMP.

I908 
Druck von Oscar Brandstetter in Leipzig. 